\title{
Need for promoting agriculture and protecting the environment
}

\author{
Ek Raj Ojha \\ Senior Sustainable Development Consultant and Visiting Professor, Kathmandu, Nepal
}

Correspondence: Dr Ek Raj Ojha, Senior Sustainable Development Consultant and Visiting Professor, Kathmandu, Nepal, Tel 977984121788, Email drekrajojha@gmail.com

Received: February 06, 2018 | Published: February 08, 2018

Copyright@ 2018 Ojha. This is an open access article distributed under the terms of the Creative Commons Attribution License, which permits unrestricted use, distribution, and reproduction in any medium, provided the original author and source are credited.

\section{Editorial}

Food is the most basic essential necessity for life. Agriculture provides people with food and many other supplementary substances and services required for sustenance, growth and development. It is fundamentally through the advancement of agriculture that many countries of the world have achieved high level of human development made possible through science and technology that were originally supported by advanced and commercial farming systems. However, there are still many countries in our world, especially in the tropical region, that lag far behind in development and do not even meet their basic food requirement. In steep and arid lands of mountainous countries in particular, availability of land suitable for profitable agricultural is shrinking in availability owing to high rise in population with finite area of suitable farmland. To make matters worse, in many land-scarce areas excessive use of land and forest resources is leading to depletion of soil nutrients and resultant reduction in farm yields, food availability and income levels, thus forcing people to out-migrate in large numbers. This causes paucity of labor force in rural agrarian areas and excessive population pressure in urban centers.
Scarcities, unfair competitions for employment and various resources such as accommodation and water among various other necessities of life along with rising expectations renders life in cities tough especially for those who are relatively poorer than others. Air and water pollution and noise have reached crisis level at many urban enclaves across many parts of the world causing health hazards, physical and social pains and economic losses to many. Solution to these problems lies at the root, i.e., the conditions in rural and remote underdeveloped areas. Therefore, it has become an imminent imperative to effectively ameliorate, improve and advance the situations in the most disadvantaged areas elsewhere first. In this endeavor, agriculture should naturally receive utmost attention and care for its rapid advancement. The most essential requirement in this regard however is to first and foremost ensure good governance, which is universally the bedrock for growth and development to take place and be sustainable. Consideration of these facts could contribute eventually to progress, prosperity, and peace in our common planet Earth as a whole for all to live in ever happily and in full harmony with their overall safe and healthy environment. 